UMTRI-2003-32

\title{
RADIANT HEAT AND \\ THERMAL COMFORT IN VEHICLES
}

Joel M. Devonshire

James R. Sayer

November 2003 


\title{
RADIANT HEAT AND \\ THERMAL COMFORT IN VEHICLES
}

\author{
Joel M. Devonshire \\ James R. Sayer
}

The University of Michigan

Transportation Research Institute

Ann Arbor, Michigan 48109-2150

U.S.A.

Report No. UMTRI-2003-32

November 2003 
Technical Report Documentation Page

\begin{tabular}{|c|c|c|}
\hline $\begin{array}{l}\text { 1. Report No. } \\
\text { UMTRI-2003-32 }\end{array}$ & 2. Government Accession No. & 3. Recipient's Catalog No. \\
\hline \multirow{2}{*}{\multicolumn{2}{|c|}{$\begin{array}{l}\text { 4. Title and Subtitle } \\
\text { Radiant Heat and } \\
\text { Thermal Comfort in Vehicles }\end{array}$}} & $\begin{array}{l}\text { 5. Report Date } \\
\text { November } 2003\end{array}$ \\
\hline & & $\begin{array}{l}\text { 6. Performing Organization Code } \\
302753\end{array}$ \\
\hline \multicolumn{2}{|l|}{$\begin{array}{l}\text { 7. Author(s) } \\
\text { Devonshire, J. and Sayer, J.R. }\end{array}$} & $\begin{array}{l}\text { 8. Performing Organization Report No. } \\
\text { UMTRI-2003-32 }\end{array}$ \\
\hline \multirow{2}{*}{\multicolumn{2}{|c|}{$\begin{array}{l}\text { 9. Performing Organization Name and Address } \\
\text { The University of Michigan } \\
\text { Transportation Research Institute } \\
\text { 2901 Baxter Road } \\
\text { Ann Arbor, Michigan 48109-2150 U.S.A. }\end{array}$}} & 10. Work Unit no. (TRAIS) \\
\hline & & 11. Contract or Grant No. \\
\hline \multirow{2}{*}{\multicolumn{2}{|c|}{$\begin{array}{l}\text { 12. Sponsoring Agency Name and Address } \\
\text { The University of Michigan } \\
\text { Industry Affiliation Program for } \\
\text { Human Factors in Transportation Safety }\end{array}$}} & 13. Type of Report and Period Covered \\
\hline & & 14. Sponsoring Agency Code \\
\hline
\end{tabular}

The Affiliation Program currently includes AGC America, Autoliv, Automotive Lighting, Avery Dennison, BMW, DaimlerChrysler, DBM Reflex, Denso, Federal-Mogul, Ford, GE, General Motors, Gentex, Guardian Industries, Guide Corporation, Hella, Honda, Ichikoh Industries, Koito Manufacturing, Labsphere division of X-Rite, Lang-Mekra North America, Magna International, Mitsubishi Motors, Muth, Nichia America, North American Lighting, OSRAM Sylvania, Philips Lighting, PPG Industries, Reflec USA, Reflexite, Renault, Samlip, Schefenacker International, Sisecam, Solutia Performance Films, Stanley Electric, TG North America, Toyota Technical Center USA, Valeo, Vidrio Plano, Visteon, 3M Personal Safety Products, and 3M Traffic Control Materials.

Information about the Affiliation Program is available at: http://www.umich.edu/ industry

16. Abstract

Two layers of an infrared-reflective (IRR) film were used in alternating combinations (no treatment, one layer, and two layers) over the driver-side window of a stationary car. In Phase 1 of the experiment, cabin air temperature was held constant at one of two levels $\left(75^{\circ} \mathrm{F}\right.$ and $90^{\circ} \mathrm{F}\left[24^{\circ} \mathrm{C}\right.$ and $\left.\left.32^{\circ} \mathrm{C}\right]\right)$ while subjects rated their thermal comfort. In Phase 2, air temperature was adjusted by fixed steps according to the subjects' responses ("too hot" or "too cold").

In Phase 1, the IRR treatment significantly improved localized thermal comfort (on the left forearm, which was exposed to direct solar irradiance), but not whole body thermal comfort (although ratings for whole body comfort followed the expected trend). In Phase 2, IRR treatment resulted in subjects indicating that they were comfortable at an average air temperature of $2.5^{\circ} \mathrm{F}\left(1.4^{\circ} \mathrm{C}\right)$ higher than in the untreated condition.

The results indicate that reducing radiant heat by the application of an IRR treatment affects subjective assessments of thermal comfort and allows occupants to maintain the same level of comfort in a warmer vehicle cabin. This may imply greater fuel economy savings than have previously been estimated because less cooling of the cabin is required in a vehicle with IRR-treated glazing. The range of conditions investigated in this study was limited, and the results should therefore be considered preliminary. Future research should examine how the following factors influence the relationships observed in this study: the percentage of IR rejection provided by the treatment, the total surface area of the treatment, the duration and amount of the subjects' irradiant exposure, and a wider range of ambient weather conditions.

\begin{tabular}{|c|c|c|c|}
\hline $\begin{array}{l}\text { 17. Key Words } \\
\text { thermal comfort, automotiv }\end{array}$ & azing, IRR, solar control & & $\begin{array}{l}\text { 18. Distribution Statement } \\
\text { Unlimited }\end{array}$ \\
\hline $\begin{array}{l}\text { 19. Security Classification (of this report) } \\
\text { None }\end{array}$ & $\begin{array}{l}\text { 20. Security Classification (of this page) } \\
\text { None }\end{array}$ & $\begin{array}{l}\text { 21. No. of Pages } \\
37\end{array}$ & 22. Price \\
\hline
\end{tabular}




\section{ACKNOWLEDGEMENTS}

Appreciation is extended to the members of the University of Michigan Industry Affiliation Program for Human Factors in Transportation Safety for support of this research. The current members of the Program are:

\begin{tabular}{|c|c|}
\hline AGC America & Mitsubishi Motors \\
\hline Autoliv & Muth \\
\hline Automotive Lighting & Nichia America \\
\hline Avery Dennison & North American Lighting \\
\hline BMW & OSRAM Sylvania \\
\hline DaimlerChrysler & Philips Lighting \\
\hline DBM Reflex & PPG Industries \\
\hline Denso & Reflec USA \\
\hline Federal-Mogul & Reflexite \\
\hline Ford & Renault \\
\hline GE & Samlip \\
\hline General Motors & Schefenacker International \\
\hline Gentex & Sisecam \\
\hline Guardian Industries & Solutia Performance Films \\
\hline Guide Corporation & Stanley Electric \\
\hline Hella & TG North America \\
\hline Honda & Toyota Technical Center, USA \\
\hline Ichikoh Industries & Valeo \\
\hline Koito Manufacturing & Vidrio Plano \\
\hline Labsphere division of X-Rite & Visteon \\
\hline Lang-Mekra North America & 3M Personal Safety Products \\
\hline Magna International & 3M Traffic Control Materials \\
\hline
\end{tabular}

We thank Carol Flannagan and Michael Flannagan for their assistance. 


\section{CONTENTS}

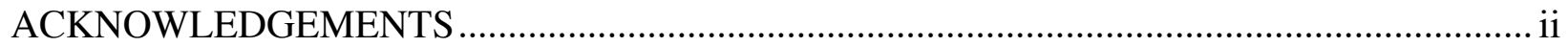

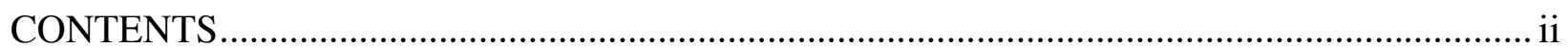

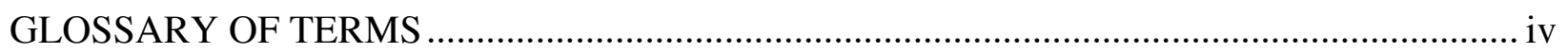

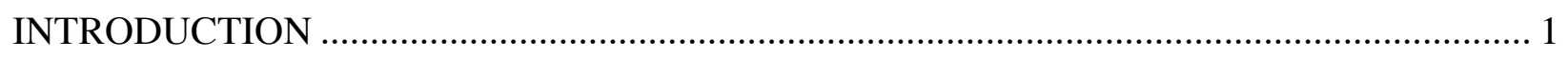

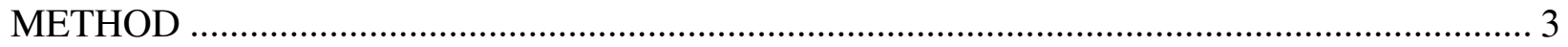

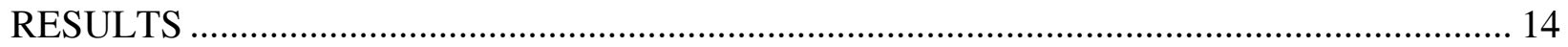

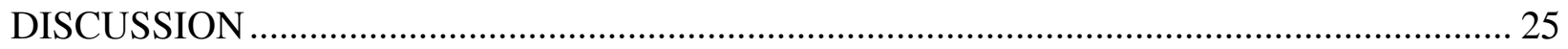

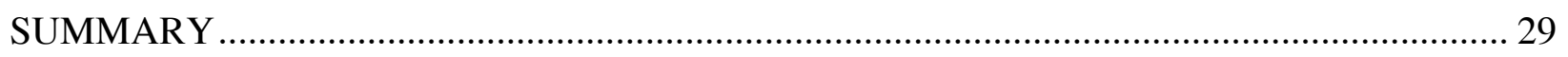

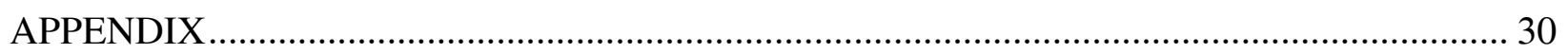

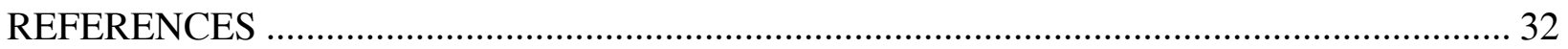




\section{GLOSSARY OF TERMS}

(Adapted from “Solar radiation basics," 2002 and "Measured radiation quantities," 2003.)

\section{General Terminology}

Irradiance: the amount (or intensity) of electromagnetic energy incident on a surface per unit time per unit area. Irradiance is measured in watts per square meter $\left(\mathrm{W} / \mathrm{m}^{2}\right)$. On the surface of the earth on a clear day, at noon, solar irradiance measures approximately $1000 \mathrm{~W} / \mathrm{m}^{2}$, depending on factors such as location (including latitude and elevation), season, time of day, and especially cloud cover.

Solar radiation: electromagnetic radiation in the spectral range of approximately 300 to 3,000 $\mathrm{nm}$ (often referred to as "shortwave" radiation). The shortest, middle, and longest wavelengths are known as ultraviolet (UV), visible, and near or shortwave infrared (IR), respectively. The spectral distribution of solar energy at sea level is roughly $3 \%$ in the UV region, $44 \%$ in the visible region, and $53 \%$ in the IR region.

Infrared (IR) radiation: refers to the 700 to $1,000,000 \mathrm{~nm}$ range in the electromagnetic spectrum. IR radiation is typically divided into three bands. Although no standard definitions of these bands exist, they are roughly defined by wavelength: near or shortwave IR is between 700 and 1,300 nm; mid-IR falls between 1,300 and 3,000 nm; and far-IR (also known as thermal or long wave IR) is between 3,000 and $1,000,000 \mathrm{~nm}$. All objects with a temperature greater than absolute zero emit infrared radiation, and hotter objects emit shorter wavelengths.

\section{Types of Measurement}

Direct solar irradiance: the solar radiation that passes directly from the sun through the atmosphere without being scattered or absorbed.

Diffuse sky solar irradiance: solar irradiance reaching the ground that has been scattered by an atmospheric constituent such as air molecules, dust, or clouds.

Downward total (global) solar irradiance: the total amount of solar irradiance on an upwardfacing horizontal surface. It is the sum of the vertical component of the direct solar irradiance and the diffuse sky irradiance. If the surface under study is tilted with respect to the horizontal, the total irradiance is the incident diffuse radiation plus the direct normal irradiance projected onto the tilted surface and ground reflected irradiance that is incident on the tilted surface. 


\section{INTRODUCTION}

Based upon geographical location, time of year, and ambient weather conditions, the air temperature inside a car that has been sitting in the sun often exceeds $100^{\circ} \mathrm{F}\left(37.8^{\circ} \mathrm{C}\right)$, and in many cases can reach as high as $140^{\circ} \mathrm{F}\left(60^{\circ} \mathrm{C}\right)$ (Young \& Van Esso, 1989; Hymore, Tweadey, \& Wozniak, 1991; Moyer, 1995). This greenhouse-like phenomenon carries implications not only for the comfort of vehicle occupants, but also for issues such as fuel economy and engine size-higher temperatures result in increased demands on the vehicle's air conditioning $(\mathrm{A} / \mathrm{C})$ system. Because as much as $70 \%$ of the total solar heat load in a vehicle arises from sunlight incident through glazing areas (Kai \& Kawasaki, 1985, as cited in Roessler \& Heckmann, 1992), automotive glazing manufacturers have sought to develop materials that can reduce solar load. One such material is infrared-reflective (IRR) glazing, a material that, as the name suggests, reflects the infrared portion of solar radiation while still transmitting most visible light.

A review of eight experimental studies found that adding IRR treatment to a vehicle's glazing can reduce cabin air temperature and surface temperatures of the dashboard and instrument panel under conditions of high solar load (Devonshire \& Sayer, 2002). Not surprisingly, the reductions in temperature were correlated with the amount of treatment used and the percentage of infrared radiation rejected by the treatment. Results from these studies also suggest that IRR treatment is more effective at maintaining cabin air temperatures than infrared-absorbing treatment (another solar-control glazing material). This is due to the lack of "re-radiation" of heat into the vehicle's cabin that is commonly observed with infrared-absorbing treatment.

Although reductions in air temperature were a consistent finding among the reviewed studies, air temperature alone may be an insufficient predictor of occupant thermal comfort. Past research suggests, for instance, that thermal comfort is associated with the combined effects of air temperature, air velocity, humidity, mean radiant temperature, clothing level, and activity level (Fanger, 1970). Moreover, none of the reviewed studies included subjective assessments of comfort, but instead relied on models of thermal comfort to predict how people might respond when an IRR treatment is used. Because existing models of thermal comfort were not developed for automotive applications, these models may give an inaccurate sense of how people would actually respond. 
Devonshire and Sayer (2003) performed an experiment designed to address some of these issues. Four otherwise identical sedans had infrared-reflective (IRR) film applied to differing sections of the cars' glazing. Two independent variables were manipulated: A/C output (two different settings) and IRR film placement (windshield and front side windows, windshield only, front side windows only, and no IRR film applied). Dependent variables included subjective assessments of thermal comfort as well as objective measures of skin temperature and cabin air temperature. Consistent with past research, presence of the film significantly decreased interior air temperatures during both a static soak and dynamic cool-down of the cars. As expected, the magnitude of this effect was larger in those conditions in which larger surface areas of film were applied. Presence of the film was also associated with a significant increase in subjective assessments of thermal comfort during a vehicle cool-down, an increase that appeared to be at least partly independent of the air temperature inside the vehicle. That is, for any given air temperature, subjective ratings of thermal comfort were better in those conditions in which the IRR film was applied.

This last finding is consistent with well established models of thermal comfort that include factors other than air temperature, and points in particular to the possible role of radiant heat in influencing ratings of comfort in an automobile. However, the study included no direct measure of radiant energy, making it difficult to quantify a relationship between air temperature and radiant heat. Further, the study examined subjective ratings of comfort in transient cooldown conditions (in which subjects entered a hot car and immediately turned on the $\mathrm{A} / \mathrm{C}$ ), but not in steady-state conditions (i.e., conditions resembling driving on the road, in which the climate remains relatively unchanged).

The present study, designed as a follow-up to Devonshire \& Sayer (2003), investigated the relationships among air temperature, radiant heat, and subjective ratings of comfort in both transient and steady-state conditions when an IRR treatment is used. The study had two phases:

Phase 1: Establish a relationship between radiant heat and subjective comfort ratings.

Hypothesis: When air temperature is held constant, subjects will find an IRR-treated condition more comfortable than an untreated condition.

Phase 2: Quantify the relationship.

Hypothesis: Subjects will require a lower air temperature in the untreated condition vs. the treated condition to maintain the same level of comfort. 


\section{METHOD}

\section{Phase 1}

\section{Independent variables}

Phase 1 consisted of a $3 \times 2 \times 2$ repeated measures design (each subject experienced all levels of the three independent variables, resulting in 12 experimental conditions per subject). Independent variables included IRR treatment, air temperature, and repetition. Levels of air temperature were blocked between subjects, and trial repetitions were randomized within subjects.

IRR treatment. Layers of an aftermarket IRR film were draped-alternating between one layer of treatment, two layers of treatment, and no treatment—over the driver-side window of the research vehicle. Specifications of the film and the method of application are described later in this section.

Air temperature. Air temperature was an average measurement of four sites within the vehicle cabin (described later in this section). Air temperature was held approximately constant at two different levels $\left(75^{\circ} \mathrm{F}\right.$ and $90^{\circ} \mathrm{F}\left[23.9^{\circ} \mathrm{C}\right.$ and $\left.\left.32.2^{\circ} \mathrm{C}\right]\right)$ by a combination of the vehicle's $\mathrm{A} / \mathrm{C}$ system and two portable electric heaters.

Repetition. Every subject experienced two repetitions of each combination of air temperature level and IRR treatment level.

\section{Dependent variables}

Objective measures. Objective measures for Phase 1 included skin temperature and total solar irradiance. Skin temperature was an average measurement, weighted according to relative surface area of skin, of four different locations on the body: neck, right scapula, left hand, and right shin (ISO 9886, 1992). Downward total solar irradiance was measured at two sites: the roof of the car (ambient measurement) and the driver-side window ledge (irradiance reaching the subject). (Irradiance reaching the subject—after reductions from the car's glazing and the IRR treatment-is referred to as net irradiance throughout the remainder of this report.) 
Subjective measures. Subjects were asked to give periodic ratings of their thermal comfort. Thermal comfort was measured with a modified version of a numerical rating scale suggested in ISO 10551 (1993). The scale is shown below.

$\begin{array}{lr}\text { Very hot } & +4 \\ \text { Hot } & +3 \\ \text { Warm } & +2 \\ \text { Slightly warm } & +1 \\ \text { Comfortable } & 0 \\ \text { Slightly cool } & -1 \\ \text { Cool } & -2 \\ \text { Cold } & -3 \\ \text { Very cold } & -4\end{array}$

Subjects used this scale to give three different ratings: overall (whole body) thermal comfort, left forearm thermal comfort, and left leg thermal comfort.

\section{Phase 2}

\section{Independent variables}

Phase 2 was also a repeated measures design, but only included one independent variable: IRR treatment. (The same three levels of treatment were used for this phase as in Phase 1.)

\section{Dependent variables}

Objective measures. In Phase 2, air temperature was treated as a dependent variable. Every two minutes, the air temperature was raised or lowered by a three-degree $(F)$ step in response to the subjects' indicated thermal sensation. The main dependent measure of interest was the average air temperature over the first two reversals of opinion (from "too hot" to "too cold," or vice versa). Skin temperature and downward total solar irradiance (measured at the same locations as Phase 1) were also included as dependent measures.

Subjective measures. Phase 2 included only one subjective measure: Subjects were periodically asked to indicate whether they were too hot or too cold. 


\section{Materials}

\section{Vehicle}

A 1993 mid-sized sedan was used in the experiment. The car's glazing and A/C system were those installed by the manufacturer. The car's A/C system included two control mechanisms: a sliding lever that controlled the temperature of the output air and a sliding control for fan speed (four levels of fan speed could be selected).

IRR film

An aftermarket IRR film was used for the experiment. Table 1 lists the specifications of the film, as provided by the manufacturer. The corresponding specifications for two layers of the film were not measured for this experiment.

Table 1

IRR film specifications.

\begin{tabular}{|l|c|}
\hline Visible light transmittance: & $77.0 \%$ \\
\hline IR rejection: & $77.1 \%$ \\
\hline UV rejection: & $99.0 \%$ \\
\hline Shading coefficient: & 0.6 \\
\hline Emissivity: & 0.6 \\
\hline U-Value: & 1.0 \\
\hline
\end{tabular}

\section{Instruments}

Insulated type-T thermocouples (shielded from radiation) were used to measure skin and air temperatures. Apogee $®$ silicon pyranometer sensors were used to measure downward total solar irradiance. Two Vornado® 800/1,500 W portable electric heaters with digital thermostats were used to control and manipulate cabin air temperature. An Iotech ${ }^{\circledR}$ data logger and laptop computer were used to collect and store all objective measurements. 
Figures 1 and 2 show the relationship between the relative spectral response of the pyranometer sensors (graph provided by the manufacturer) and the total solar spectrum (the wavelength distribution of solar radiation reaching the earth's surface). Notice that the pyranometer was only responsive to wavelengths at or below 1,200 nm. While this represents only $21.7 \%$ of the total infrared distribution of solar energy, it does include nearly the entire range of shortwave infrared (approximately 700-1,300 nm).

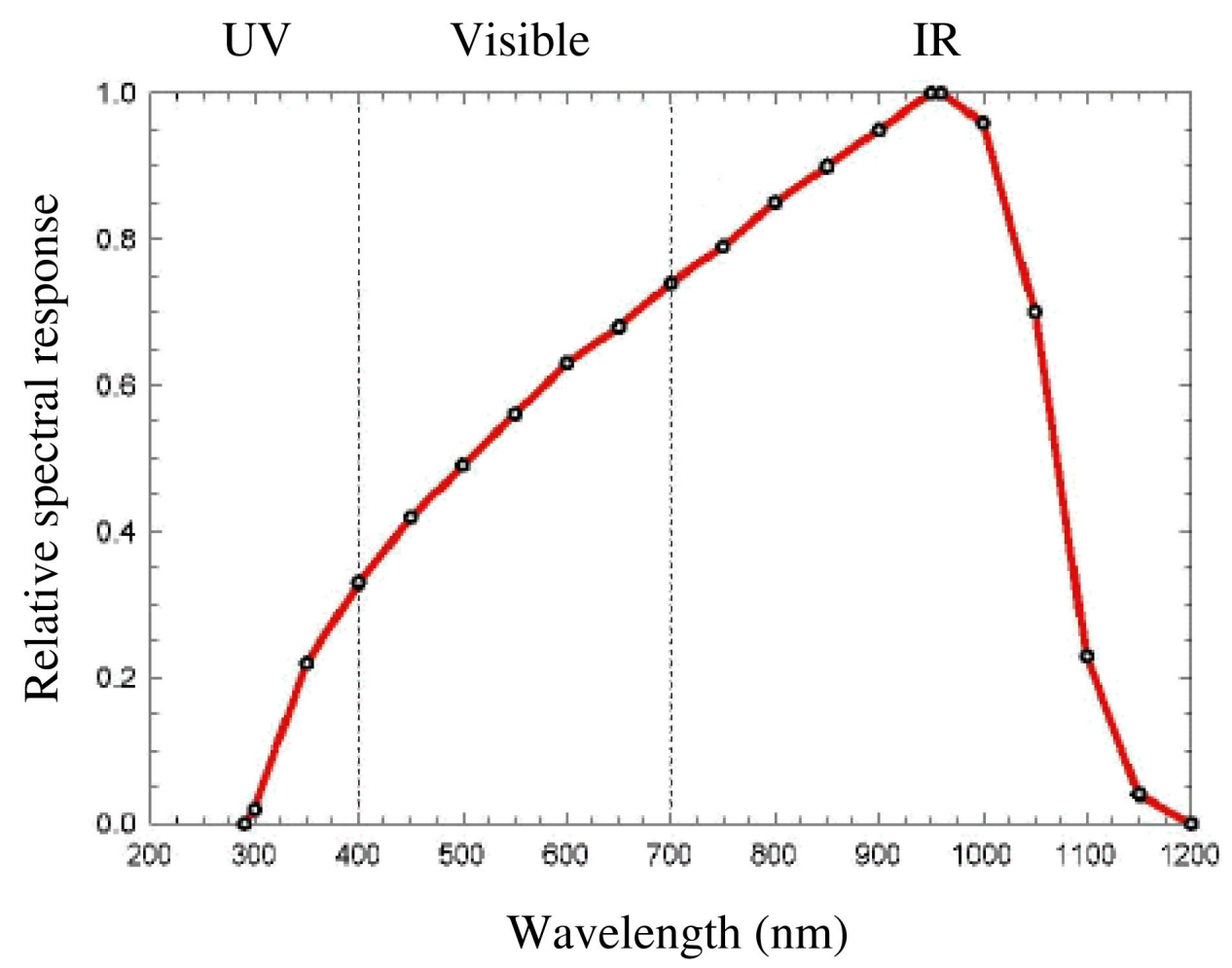

Figure 1. Spectral response of the Apogee ${ }^{\circledR}$ pyranometer sensor. 
As Figure 2 illustrates, the intensity of solar radiation above 1,200 $\mathrm{nm}$ is relatively small and falls rapidly as wavelength increases (the top line represents global irradiance).

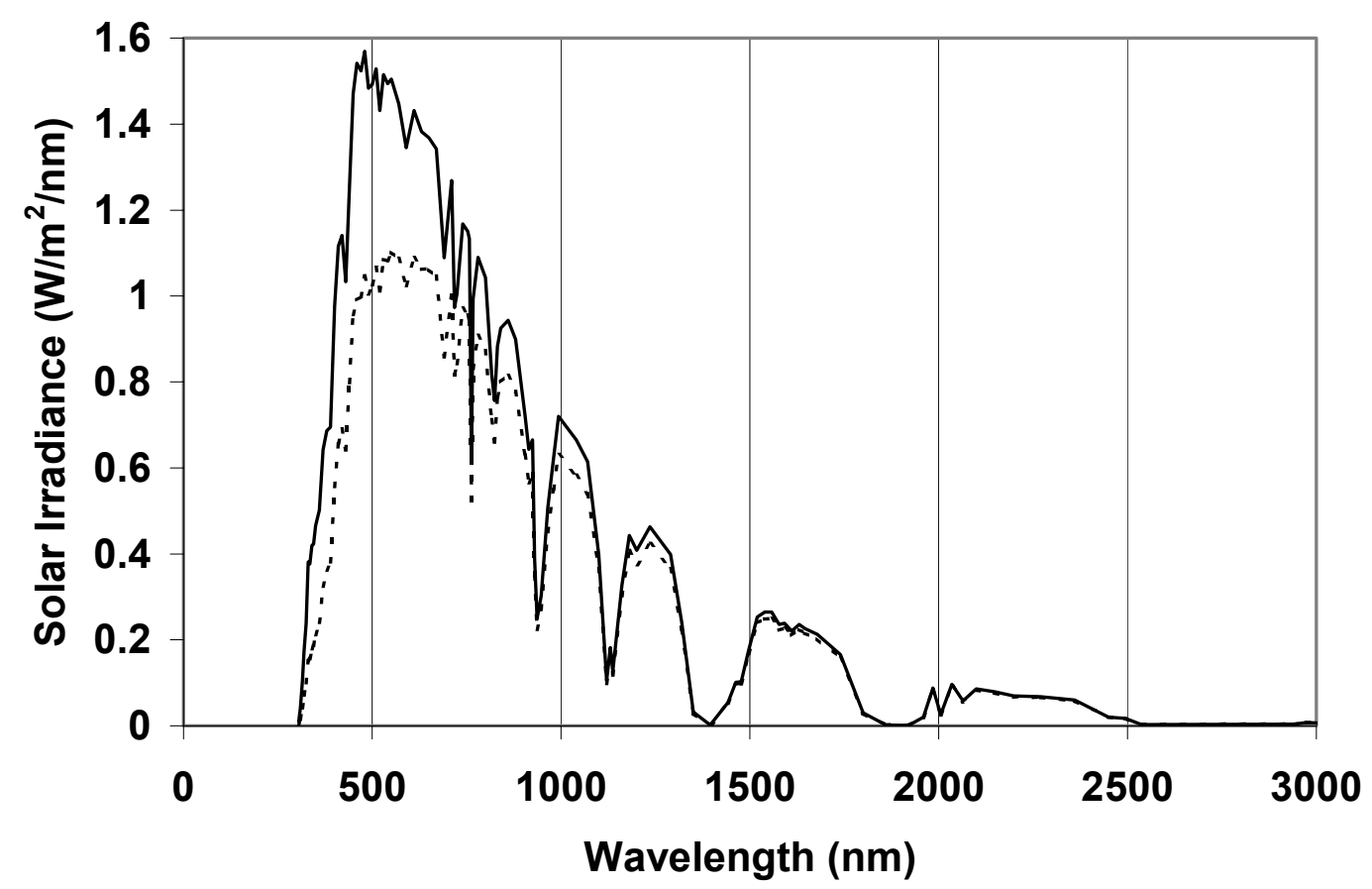

Figure 2. Standard solar spectrum (ASTM E891, E892; as cited in "Solar radiation basics," 2002). The solid and dotted lines represent total and direct irradiance, respectively.

\section{Experimental setup}

The experiment was performed outdoors at UMTRI. The car remained stationary, facing southwest, throughout the duration of the experiment. The car's roof, windshield, rear window, and passenger-side front and back windows were covered with aluminum foil (see Figure 3) in order to better control the cabin air temperature and to eliminate the possibility of solar radiation hitting the driver from multiple angles. One pyranometer sensor was mounted in on the car's roof (level to gravity). 


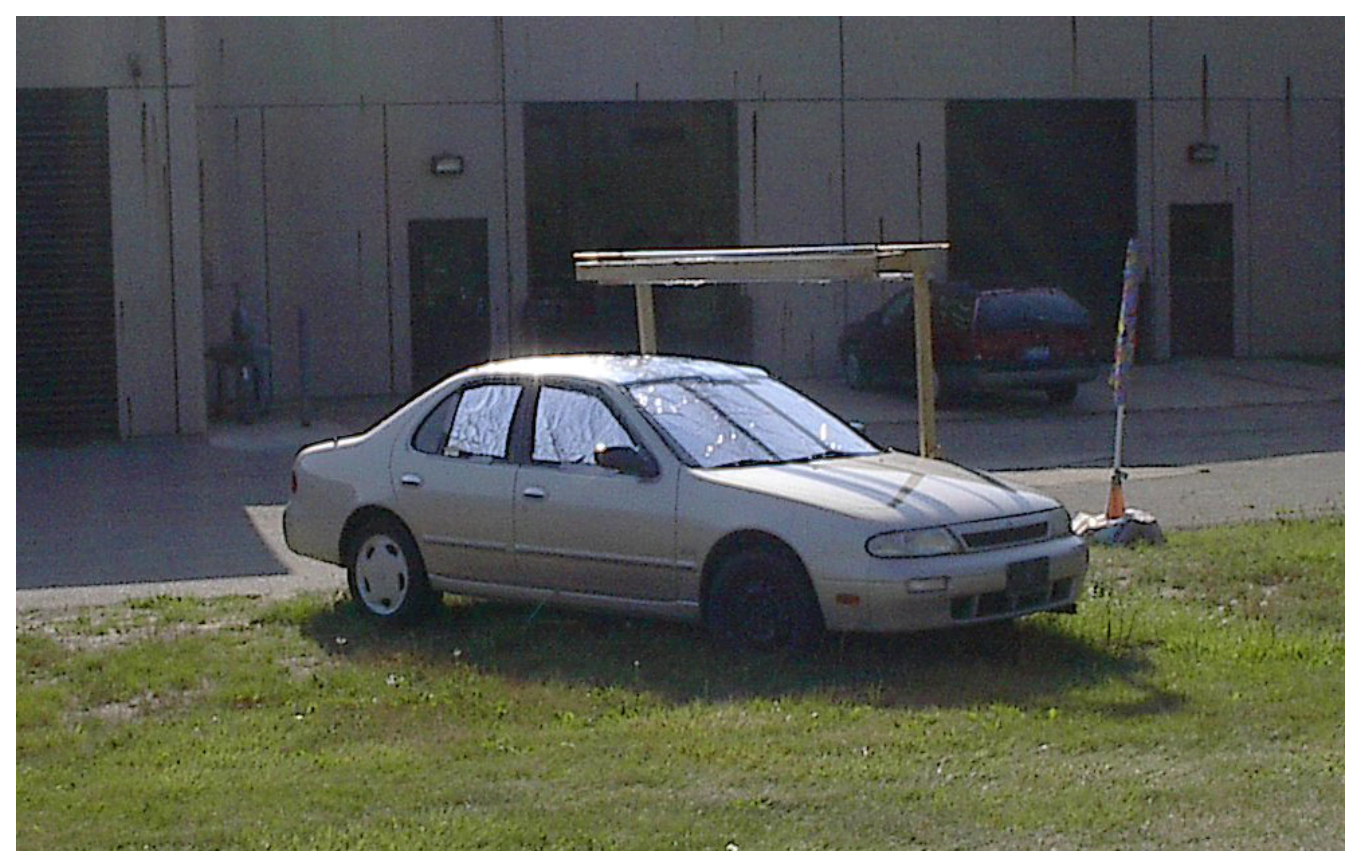

Figure 3. Position of the research vehicle.

Figure 4 shows the placement of thermocouples and pyranometers inside the car. The four thermocouples were mounted on the ceiling directly above the subject, on the driver-seat beneath the headrest, on the front of the steering wheel, and beneath the instrument panel near the brake pedal.

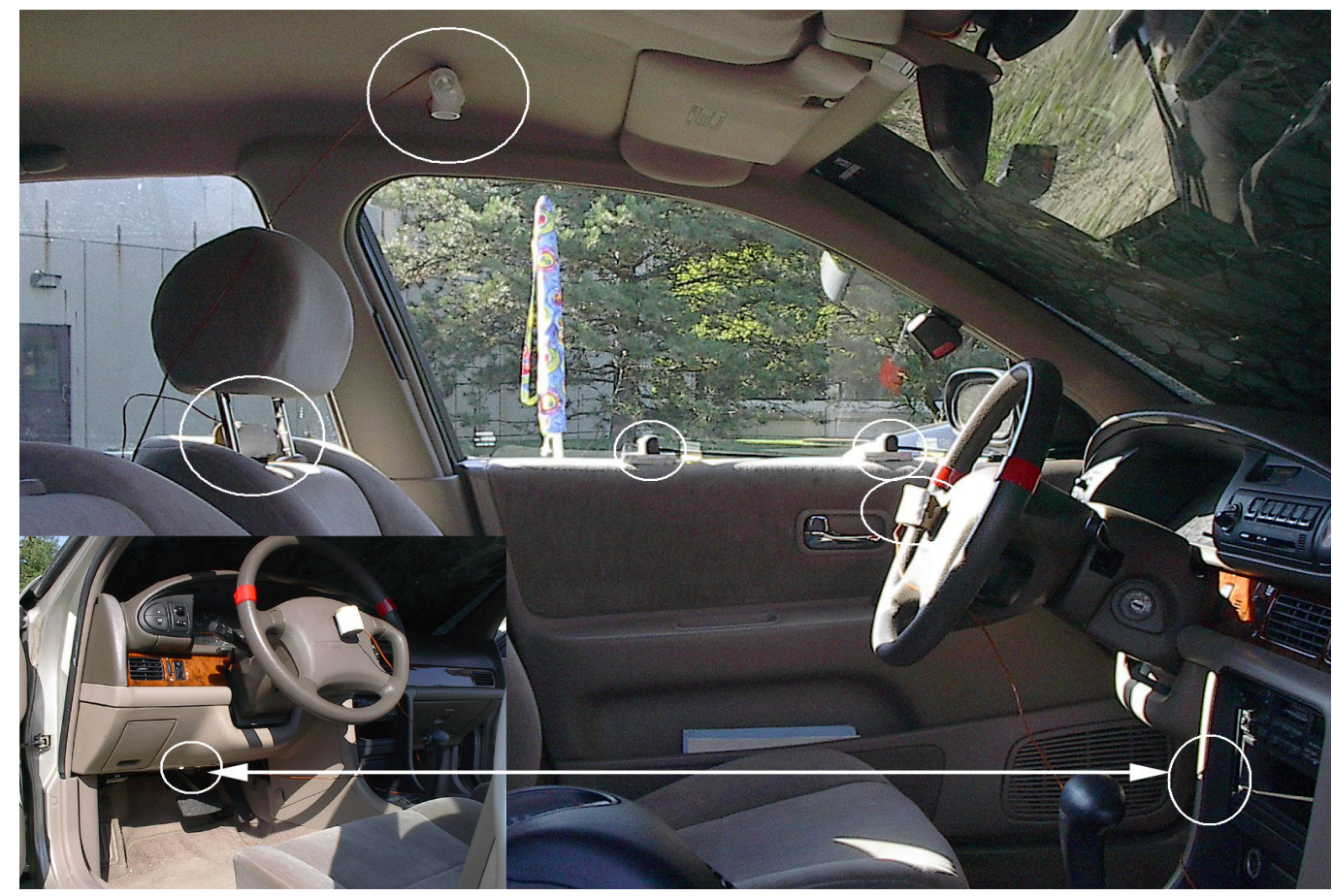

Figure 4. Interior of the car. Circles highlight the positions of thermocouples and pyranometers. 
Net irradiance consisted of an average measurement of the two pyranometers located inside the car on the driver-side window ledge (both sensors were level to gravity). Radiation shields for the thermocouples were constructed from cardboard tubing covered with white tape. $\mathrm{A} / \mathrm{C}$ vents were directed away from the driver-seat.

Two portable electric heaters were located inside the vehicle. One heater was on the front passenger seat, while the other was located on the floor directly behind the driver-seat. Both heaters were positioned so that direct airflow from the heaters' fans would not hit the subject.

Figure 5 shows the frame used to apply the IRR treatment. The frame consisted of wooden boards and two spring rollers (typically used for window shades). Each roller held a $5 \mathrm{x}$ $8 \mathrm{ft}$. $(1.5 \times 2.4 \mathrm{~m})$ sheet of the IRR film. The two sheets could be extended independently to provide single or double IRR treatment (see Figure 6). As Figure 6 illustrates, the frame was bent at a $90^{\circ}$ angle near the top so that no shadow would be cast across the window by the frame, and so that the film could cover as wide an angle as possible.

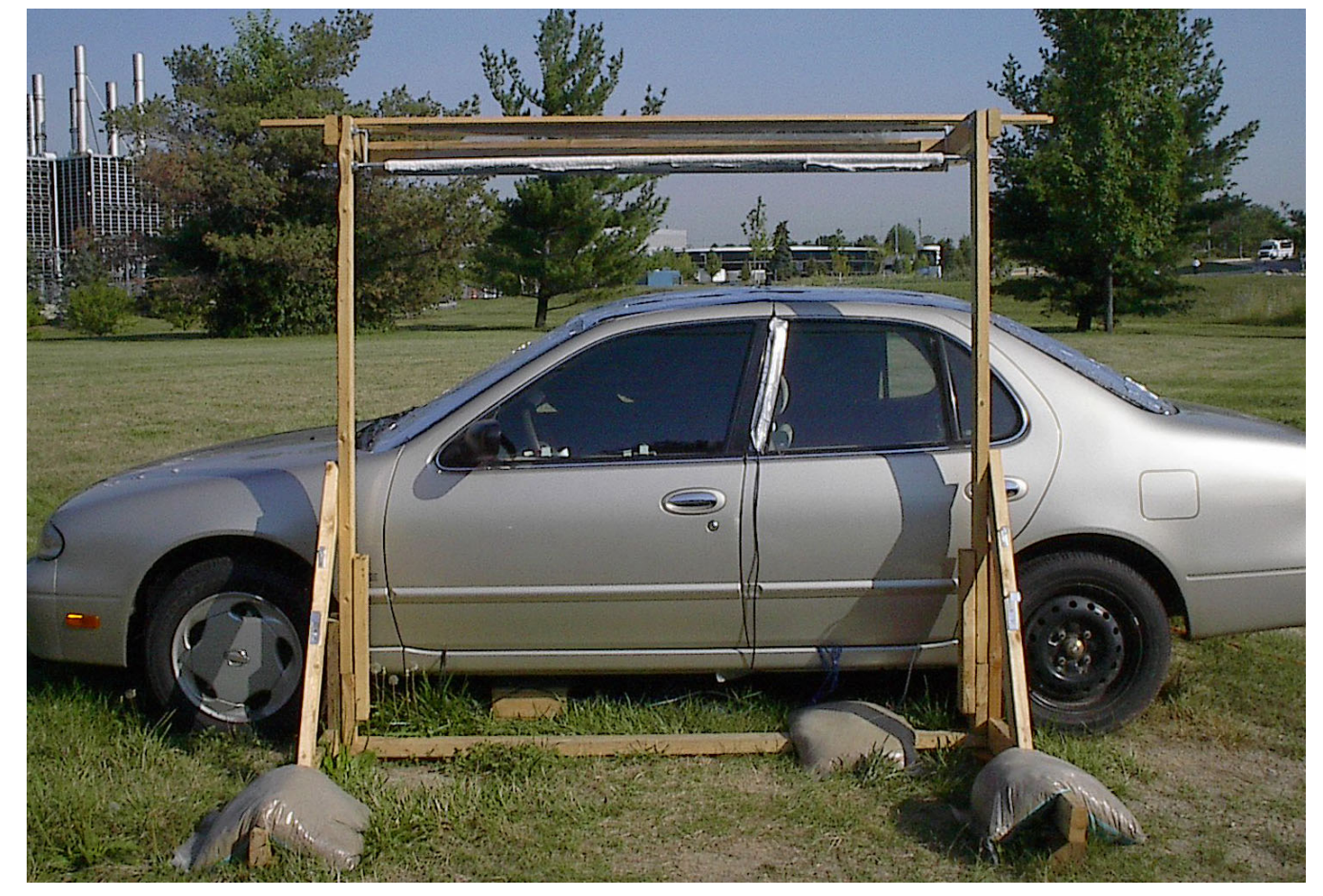

Figure 5. IRR treatment frame. The frame allowed one or two sheets of IRR film to be draped across the driver-side window. 


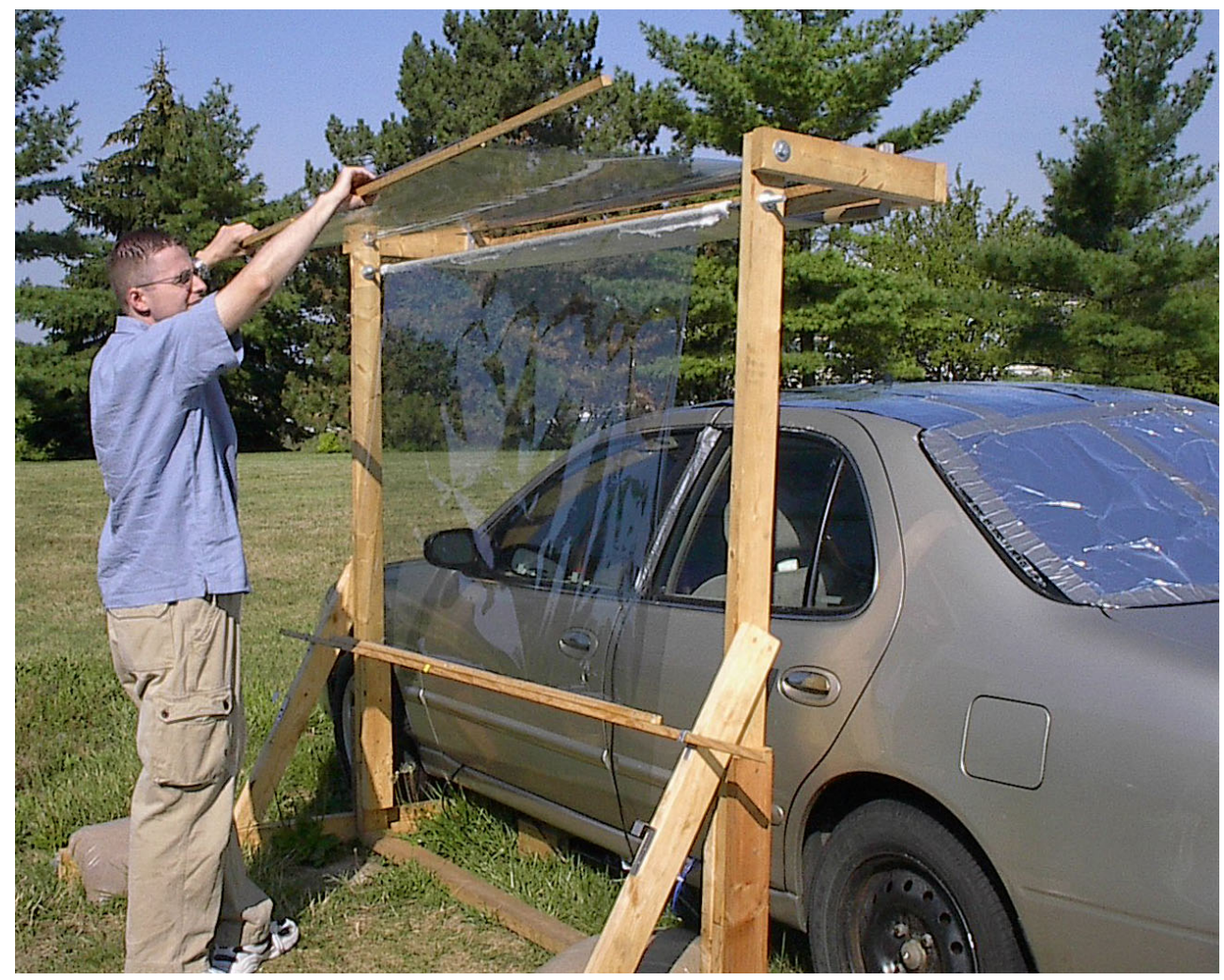

Figure 6. IRR treatment application. Hooks near the bottom of the frame held each layer in place and allowed the two layers to be overlapped.

\section{Subjects}

There were 12 paid subjects, recruited from a list of potential volunteers that is maintained by UMTRI. Six were in a younger age group (between 18 and 30 years old with a mean age of 21.7 years) and six were in an older age group (between 40 and 60 years old with a mean age of 49.0 years). The groups were balanced for gender, and all subjects were licensed drivers. Subjects were asked to wear their own undergarments, shorts, a white T-shirt, socks, and shoes (no open-toed shoes or sandals). The subjects were given these items to wear if they did not own them. During the experiment, subjects had thermocouples taped to their skin, with connectors attached to their clothes via safety pins. 


\section{Procedure}

All experimental sessions were conducted between July 16 and August 19, 2003. Each session began at 10:00 a.m. and lasted for approximately three hours.

During both phases of the experiment, the car was left running with the $\mathrm{A} / \mathrm{C}$ turned on. Approximately one hour before each session, the cabin of the car was brought to the desired air temperature range by adjusting the portable heaters and the car's A/C. Once the desired temperature range was reached, the experimenter monitored the air temperature continuously, making adjustments as needed. These manual adjustments to air temperature were made throughout both phases of the experiment. In Phase 1, the goal was to keep the air temperature at a constant level; in Phase 2, the goal was to change the air temperature by fixed steps in response to the subjects' thermal sensation. Adjustments were made primarily to the thermostats of the portable heaters, although in certain cases the air temperature mechanism of the car's A/C was also adjusted (e.g., during parts of Phase 2, when rapid cooling of the cabin was required).

The fan speed and vent positions of the car's A/C remained fixed throughout the experiment with one exception: The fan speed was changed by one level between the $75^{\circ} \mathrm{F}$ and $90^{\circ} \mathrm{F}$ blocks of trials in Phase 1 . (The $75^{\circ} \mathrm{F}$ condition required a higher fan speed to maintain the air temperature in the car.)

\section{Phase 1}

Phase 1 was run in two temperature blocks (a $75^{\circ} \mathrm{F}$ block and a $90^{\circ} \mathrm{F}$ block). Each block consisted of six consecutive two-minute trials, during which IRR treatment was manipulated. At the beginning of each block of trials, the subject was led from the UMTRI building (a controlled climate) to the car. The subject was instructed to approach the driver-side door, but to wait for the experimenter to signal before entering the car. When the experimenter signaled, both the subject and the experimenter entered the car simultaneously (the experimenter entered through the rear passenger-side door) and closed the doors as quickly as possible.

Once inside the car, the subject was asked to put on a blindfold (Figure 7) and to place his/her hands at predefined locations on the steering wheel. The subject then waited about 10 to 15 seconds for the experimenter to plug in the skin temperature thermocouple connectors. 


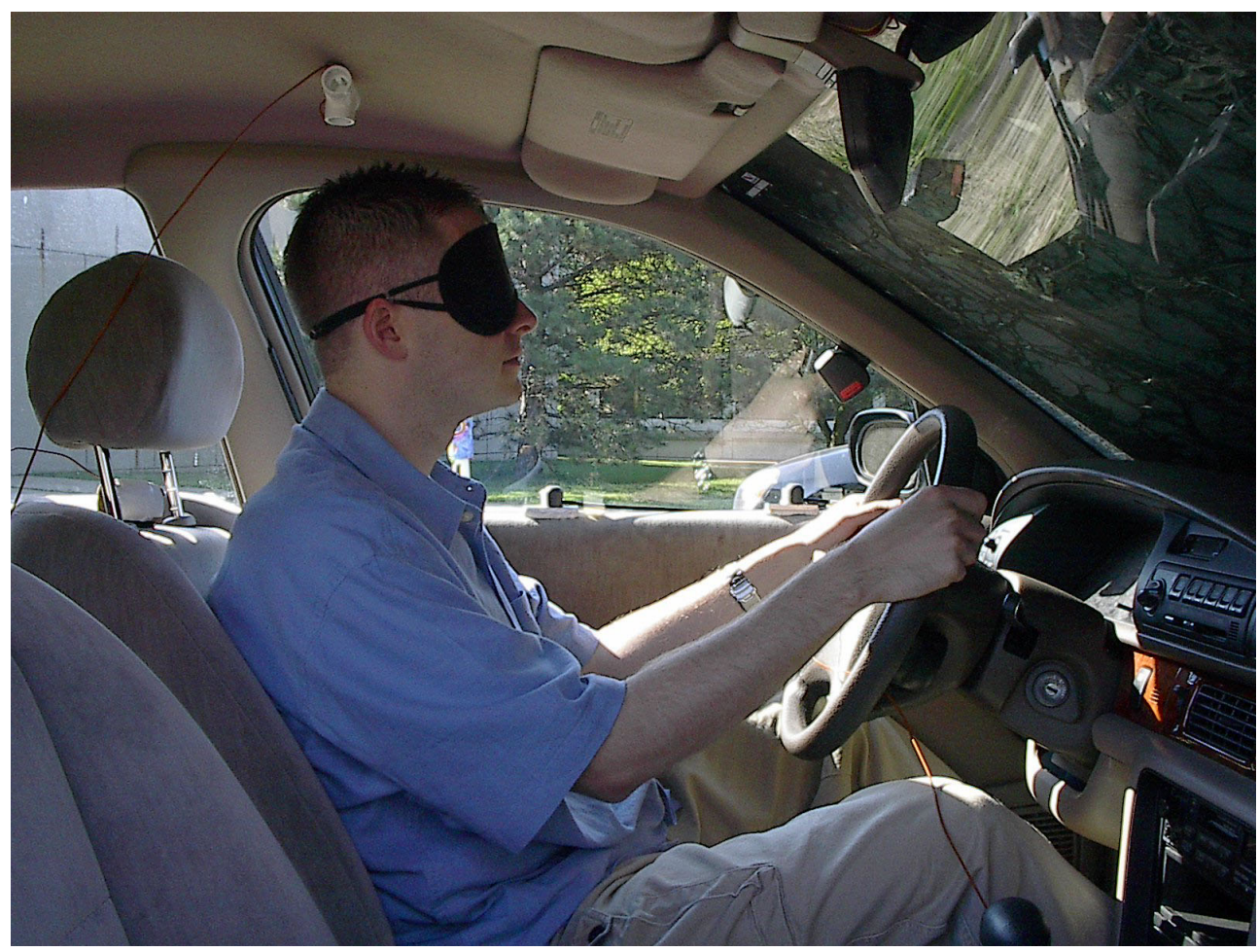

Figure 7. Subject seated in car.

Notice in Figure 7 that the left side of the subject is exposed to direct solar radiation while the right side is shaded. The session length and car position were such that these conditions were present the entire time the subject was in the car.

While the subject was seated in the driver-seat, the IRR treatment was changed every two minutes by an assistant outside. After two minutes of each IRR treatment, the experimenter would ask the subject to give three subjective ratings of thermal comfort (whole body, left forearm, and right forearm) before the next treatment was applied. When the block of six trials was complete, the subject was disconnected from the thermocouples and led back inside the UMTRI building for 10 minutes of temperature adaptation before the next block of trials.

\section{Phase 2}

Phase 2 consisted of only three trials, each of which began at an initial $90^{\circ} \mathrm{F}$ air temperature and lasted 20 minutes. Each trial represented a different level of IRR treatment. Phase 2 began exactly the same way as Phase 1: The subject was led to the car at the beginning of each trial, and instructed to enter the car quickly, put on the blindfold, and place his/her hands 
on the steering wheel. The skin temperature thermocouples were then connected and the trial began.

For this phase of the experiment, the subject was instructed to indicate whether he/she was too hot or too cold every two minutes. If the subject indicated that he/she was too hot, the experimenter lowered the air temperature by approximately three degrees. If the subject indicated that he/she was too cold, the experimenter raised the air temperature by approximately three degrees. The subject was instructed to choose between the two alternatives (too hot or too cold); the subject was not allowed to give answers such as "perfect" or "comfortable." After 20 minutes, the trial was complete and the subject was led back to the UMTRI building.

The exact wording of the instructions that were read to the subjects is included in the appendix. 


\section{RESULTS}

\section{Phase 1}

\section{Covariates}

\section{Ambient irradiance}

Although all sessions were run on sunny days, there were some instances of scattered cloud cover and/or haze while Phase 1 was in progress. This is illustrated in Figure 8, which shows ambient irradiance during each day of the experiment (i.e., for each subject).

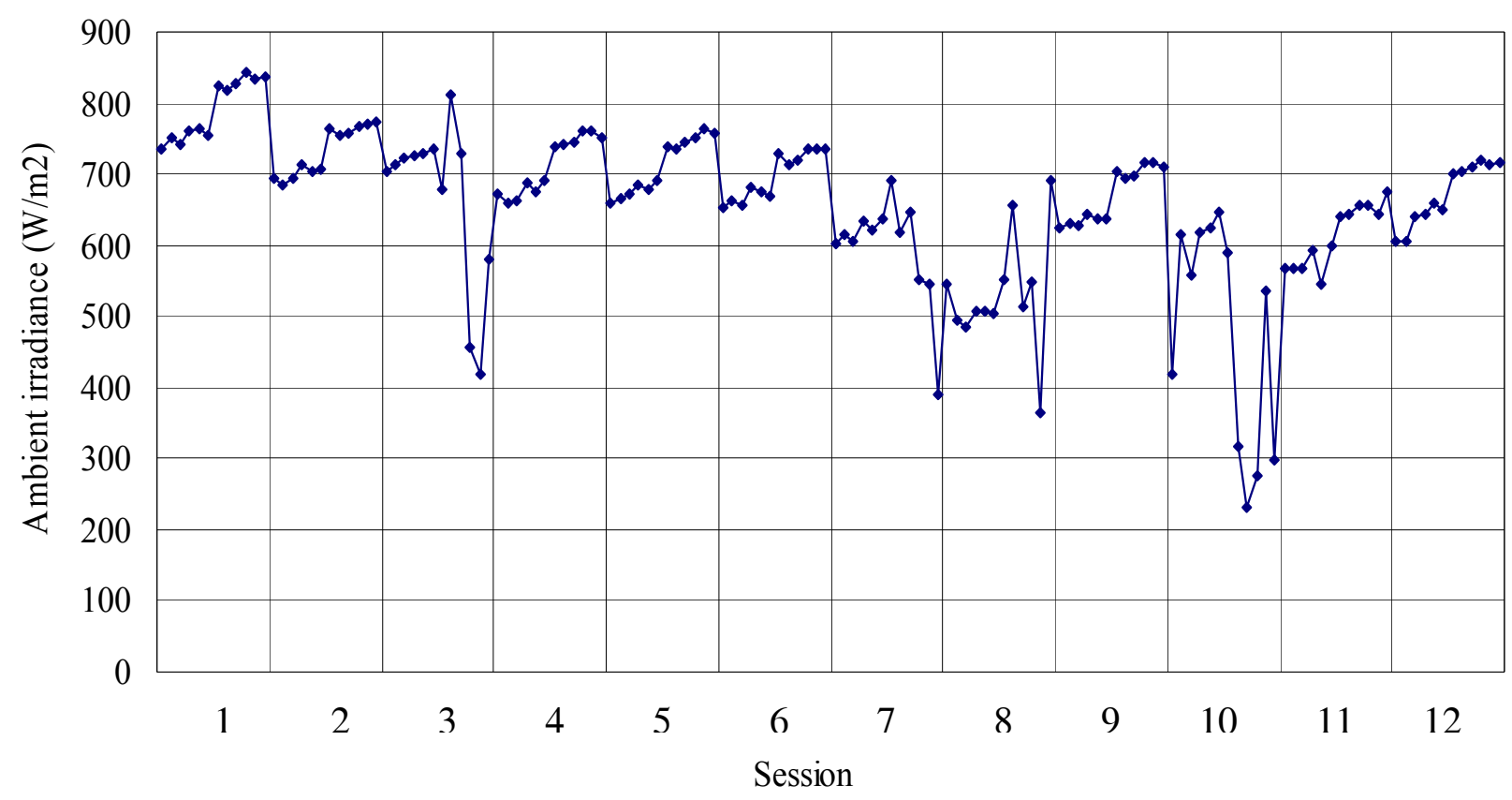

Figure 8. Ambient irradiance during Phase 1 of each session.

Although a repeated measures ANOVA showed no significant differences in ambient irradiance among experimental conditions, ambient irradiance was controlled for in all analyses of Phase 1 data. (An alpha level of .05 was used for all statistical tests.) Ambient irradiance was treated as a time-varying covariate (since it was measured continuously throughout Phase 1 of the experiment). 


\section{Air temperature}

Figure 9 shows the air temperature blocks during Phase 1 of each session. Session 1, for example, began with a $75^{\circ} \mathrm{F}$ block and was followed by a $90^{\circ} \mathrm{F}$ block, while Session 2 began with a $90^{\circ} \mathrm{F}$ block and was followed by a $75^{\circ} \mathrm{F}$ block. (Each data point represents the average air temperature over a two-minute trial.)

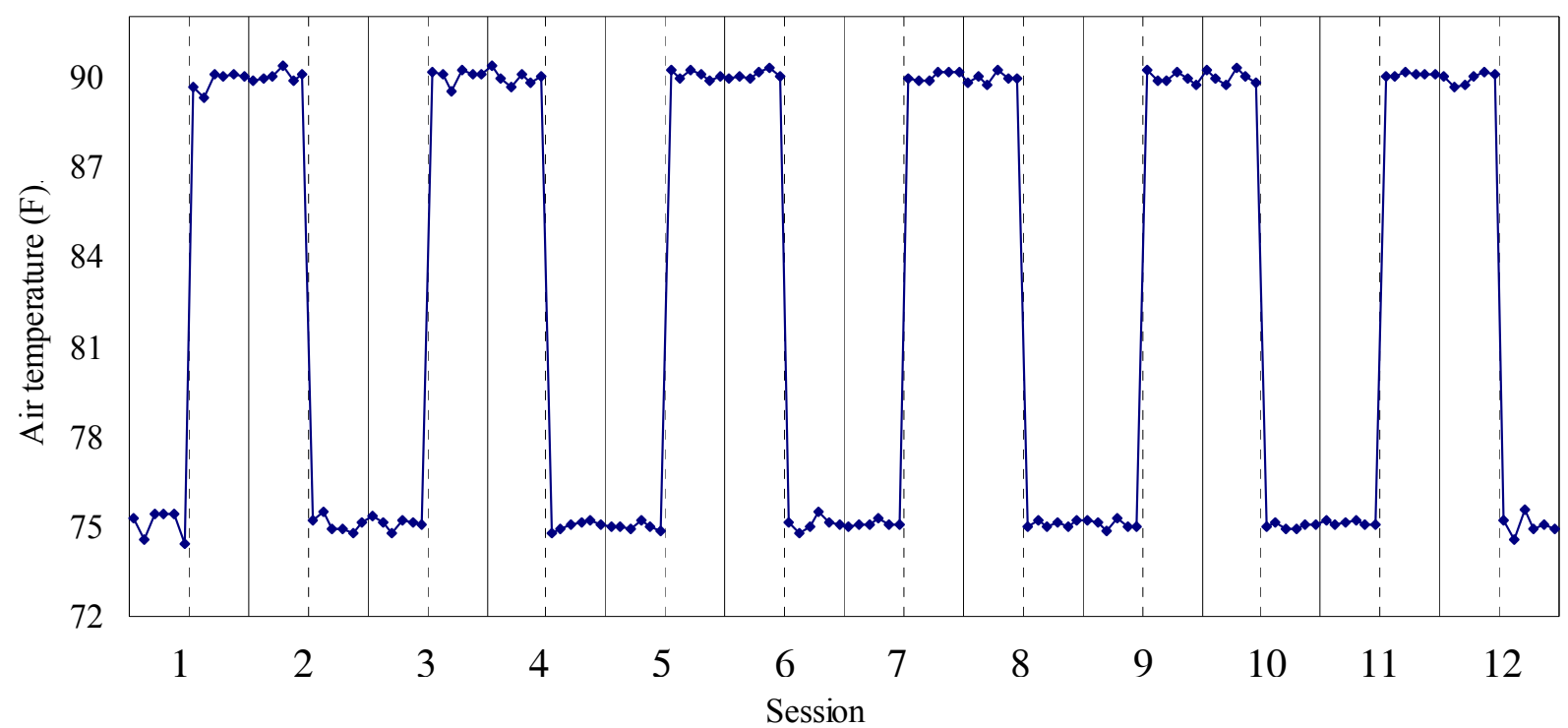

Figure 9. Air temperature blocks during Phase 1 of each session day.

As mentioned previously, the intention in Phase 1 was to manipulate levels of IRR treatment while keeping air temperature constant. To determine whether there were any significant differences in air temperature among IRR treatment conditions or trial repetitions, a repeated measures ANOVAs was performed on air temperature, using IRR treatment, trial repetition, and temperature level $\left(75^{\circ}\right.$ or $\left.90^{\circ}\right)$ as within-subjects factors and age and gender as between-subjects factors. There were significant effects of IRR treatment, $F(2,16)=9.9$, $p<.01$, and trial repetition, $F(1,8)=6.8, p<.05$. The estimated marginal means for both of these factors are listed in Table 2. 
Table 2

Phase 1 air temperature among treatment and trial repetitions.

\begin{tabular}{|c|c|c|}
\hline Condition & ${ }^{\circ} \mathrm{F}$ & ${ }^{\circ} \mathrm{C}$ \\
\hline \hline No treatment & 82.61 & 28.12 \\
\hline One layer & 82.50 & 28.06 \\
\hline Two layers & 82.48 & 28.04 \\
\hline \hline Repetition 1 & 82.49 & 28.05 \\
\hline Repetition 2 & 82.51 & 28.06 \\
\hline
\end{tabular}

Bonferroni tests of pairwise comparisons showed that the air temperature for the control (no treatment) condition was significantly different from those of the one- and two-layer conditions. However, as Table 2 shows, the magnitudes of the differences are small (e.g, $0.13^{\circ} \mathrm{F}$ or $0.08^{\circ} \mathrm{C}$ between the control and two-layer conditions). While from a practical standpoint these differences are probably negligible, the residual variance of air temperature within nominal temperature conditions $\left(75^{\circ}\right.$ vs. $\left.90^{\circ}\right)$ was treated as a time-varying covariate for all analyses of Phase 1 data.

\section{Statistical analysis}

All analyses for Phase 1 were performed using SPSS linear mixed-effects models (MIXED). The MIXED procedure handles correlated data and unequal variances, and is based on the maximum likelihood (ML) and restricted maximum likelihood (REML) methods (SPSS technical report, 2002). All models were first fit with every possible main effect and two-way interaction. The models were then refit to exclude the two-way interactions that were nonsignificant. Furthermore, all models initially included a random effect of subject, which was removed from the model if the associated Wald statistic was nonsignificant.

Statistically significant results are reported here only if they are relevant to the hypotheses being tested. Some significant interaction effects, for example, are not reported because they have no direct bearing on the research questions. 


\section{Objective measures}

\section{Net irradiance}

Table 3 shows net irradiance $\left(\mathrm{W} / \mathrm{m}^{2}\right)$ for each level of IRR treatment, after controlling for differences in ambient irradiance and air temperature.

Table 3

Phase 1 net irradiance for each level of IRR treatment.

\begin{tabular}{|c|c|}
\hline Condition & $\mathrm{W} / \mathrm{m}^{2}$ \\
\hline \hline No treatment & 357.90 \\
\hline One layer & 232.21 \\
\hline Two layers & 163.81 \\
\hline
\end{tabular}

As expected, net irradiance decreased as the amount of IRR treatment increased. A mixed-effects repeated measures analysis of covariance (ANCOVA) showed a main effect of IRR treatment on net irradiance, $F(2,67.1)=663.6, p<.001$. Bonferroni tests of pairwise comparisons showed that each level of IRR treatment was significantly different from the other levels. Notice Table 3 shows that the reductions in irradiance for the layers of treatment are approximately proportional, $35.1 \%$ between no treatment and one layer of treatment, and $29.5 \%$ between one and two layers.

It is also worth noting that the car's window reduced ambient irradiance by about $45 \%$, which is why the net irradiance figures in Table 3 are relatively low.

\section{Skin temperature}

A mixed-effects ANCOVA was performed on skin temperature that included the factors of age group, gender, air temperature, repetition, and IRR treatment, controlling for variability of air temperature and ambient irradiance. The analysis showed no significant effect of IRR treatment on skin temperature. The effect of air temperature, however, was significant, $F(1$, $63.6)=290.8, p<.001$. Mean skin temperature in the $75^{\circ} \mathrm{F}$ condition was cooler than in the $90^{\circ}$ F condition $\left(88.35^{\circ} \mathrm{F}\right.$ vs. $92.06^{\circ} \mathrm{F}$, respectively) $\left(31.31^{\circ} \mathrm{C}\right.$ vs. $\left.33.37^{\circ} \mathrm{C}\right)$.

Gender also had a significant effect on skin temperature, $F(1,65.7)=12.4, p<.01$. Females had a mean skin temperature of $90.59^{\circ} \mathrm{F}\left(32.55^{\circ} \mathrm{C}\right)$, while males had a mean skin temperature of $89.81^{\circ} \mathrm{F}\left(32.12^{\circ} \mathrm{C}\right)$. 


\section{Subjective measures}

\section{Ratings at each body location}

Table 4 shows mean comfort ratings by body location (left forearm, whole body, and left leg) collapsed across IRR treatments, repetitions, and air temperature levels. Subjective comfort ratings roughly corresponded to the amount of radiant exposure at each body location. Recall, for example, that the subjects' left forearms were exposed to direct radiation while the subjects' left legs were at least partially shaded.

Table 4

Phase 1 mean comfort rating for each body location.

\begin{tabular}{|c|c|}
\hline Body location & Rating \\
\hline \hline Left forearm & 1.69 \\
\hline Whole body & 1.09 \\
\hline Left leg & 0.92 \\
\hline
\end{tabular}

\section{Left forearm comfort}

A mixed-effects repeated measures ANCOVA was performed on the left forearm subjective rating with factors of age group, gender, air temperature, repetition, and IRR treatment, controlling for variability of air temperature and ambient irradiance. There was a significant effect of IRR treatment on the left forearm rating, $F(2,67.3)=9.4, p<.001$. Table 5 shows the estimated marginal means (equated on the two covariates) for the left forearm rating at each level of IRR treatment. Ratings decreased (indicating increased comfort) as more IRR treatment was applied. Bonferroni tests of pairwise comparisons showed that the mean rating for the control condition was significantly different from ratings of both the one- and two-layer conditions; however, the difference between mean ratings of the one- and two-layer conditions was nonsignificant. This is consistent with the diminishing returns of the IRR treatment's effect on net irradiance. 
Table 5

Phase 1 mean left forearm rating for each level of IRR treatment.

\begin{tabular}{|c|c|}
\hline Condition & Rating \\
\hline \hline No treatment & 2.25 \\
\hline One layer & 1.52 \\
\hline Two layers & 1.30 \\
\hline
\end{tabular}

As one might have expected, there was also a significant effect of air temperature on the left forearm rating, $F(1,67.3)=101.5, p<.001$. The left forearm had a mean subjective rating of 0.75 in the $75^{\circ} \mathrm{F}$ condition and 2.63 in the $90^{\circ} \mathrm{F}$ condition. There were no effects of age group or gender on the left forearm rating.

\section{Left leg comfort}

A mixed-effects ANCOVA was run on the left leg subjective rating with factors of age group, gender, air temperature, repetition, and IRR treatment, controlling for variability of air temperature and ambient irradiance. Although the effect of IRR treatment on the left leg rating was nonsignificant $(p=.78)$, the ratings followed the expected trend, as Table 6 shows.

Table 6

Phase 1 mean left leg rating for each level of IRR treatment.

\begin{tabular}{|c|c|}
\hline Condition & Rating \\
\hline \hline No treatment & 0.99 \\
\hline One layer & 0.95 \\
\hline Two layers & 0.82 \\
\hline
\end{tabular}

Similar to the left forearm rating, the effect of air temperature on the left leg rating was significant, $F(1,65.2)=95.2, p<.001$. The mean rating in the $75^{\circ} \mathrm{F}$ condition was -0.02 while the mean rating in the $90^{\circ} \mathrm{F}$ condition was 1.87 . There were no significant effects of age group or gender on the left leg subjective rating.

\section{Whole body comfort}

A mixed-effects ANCOVA was run on the whole body thermal comfort subjective rating with factors of age group, gender, air temperature, repetition, and IRR treatment, controlling for 
variability of air temperature and ambient irradiance. The main effect of IRR treatment was nonsignificant $(p=.67)$, although the mean ratings were in the expected direction (ratings decreased when IRR treatment was applied). This is illustrated in Table 7.

Table 7

Phase 1 mean whole body rating for each level of IRR treatment.

\begin{tabular}{|c|c|}
\hline Condition & Rating \\
\hline \hline No treatment & 1.22 \\
\hline One layer & 1.09 \\
\hline Two layers & 0.96 \\
\hline
\end{tabular}

Although the main effect of treatment was nonsignifant, the interaction between IRR treatment and trial repetition was significant, $F(2,67.8)=5.2, p<.01$. Table 8 displays the estimated marginal means (equated on the two covariates) for this interaction. Notice that for the control condition, subjective ratings increased as a function of repetition, while the reverse was true for the one- and two-layer conditions.

Table 8

Phase 1 mean whole body subjective ratings: IRR treatment by repetition.

\begin{tabular}{|c|c|c|}
\hline Treatment & Repetition & Rating \\
\hline \hline \multirow{2}{*}{ No treatment } & 1 & 1.11 \\
\cline { 2 - 3 } & 2 & 1.35 \\
\hline \multirow{2}{*}{ 1 layer } & 1 & 1.13 \\
\cline { 2 - 3 } & 2 & 1.05 \\
\hline \multirow{2}{*}{ 2 layers } & 1 & 1.18 \\
\cline { 2 - 3 } & 2 & 0.74 \\
\hline
\end{tabular}

Similar to the left forearm and left leg ratings, the effect of air temperature was significant, $F(1,66.2)=157.7, p<.001$. The mean whole body comfort rating was -0.13 in the $75^{\circ} \mathrm{F}$ condition and 2.3 in the $90^{\circ} \mathrm{F}$ condition. 


\section{Phase 2}

\section{Preliminary summary}

In order to examine the frequency distribution of hot/cold responses as a function of time and IRR treatment condition in Phase 2, data were summarized in terms of the trials on which the first reversal of opinion occurred for each subject (i.e., the subject switched from a response of "too hot" to a response of "too cold"). By using this method, it was possible to answer the following question: For each IRR treatment condition, at any given time, how many subjects had not yet reached an implied level of thermal comfort?

Table 9 shows the frequency of "too hot" responses by IRR treatment condition and time (collapsed across all subjects). At two minutes into the trial for any IRR condition, all 12 subjects responded that it was too hot (recall that each trial began at $90^{\circ} \mathrm{F}$ ). As expected, the frequency of hot responses decreased as a function of time (as the air temperature went down). Notice, however, that there are differences in the distribution of hot responses among IRR treatment conditions as time progresses. For example, after 12 minutes into the trial, no subjects reported the two-layer condition as too hot. At the end of the trial (at 20 minutes), there were still two subjects who reported the control (no treatment) condition as too hot, while no subjects reported the one- or two-layer conditions as too hot.

The distributions of hot responses over time are also different between the one- and twolayer conditions. For example, at least one subject found the one-layer condition too hot until 20 minutes into the trial, compared to 14 minutes in the two-layer condition. 
Table 9

Frequency of "too hot" responses by IRR treatment and time.

\begin{tabular}{|c|c|c|c|}
\hline Time (min) & No treat & 1 layer & 2 layers \\
\hline \hline 2 & 12 & 12 & 12 \\
\hline 4 & 12 & 12 & 12 \\
\hline 6 & 11 & 9 & 10 \\
\hline 8 & 10 & 5 & 7 \\
\hline 10 & 7 & 3 & 3 \\
\hline 12 & 5 & 2 & 2 \\
\hline 14 & 3 & 1 & 0 \\
\hline 16 & 2 & 1 & 0 \\
\hline 18 & 2 & 1 & 0 \\
\hline 20 & 2 & 0 & 0 \\
\hline
\end{tabular}

\section{Quantitative analysis}

In Phase 2, air temperature inside the vehicle cabin was a dependent variable (indirectly controlled by subjects). Consequently, there was only one covariate in Phase 2: ambient irradiance. Mixed-effects repeated measures ANCOVAs were used to analyze Phase 2 data while controlling for any differences in ambient irradiance.

For purposes of Phase 2 data analysis, "comfort" was considered to be reached between the time a subject made the first and second reversals of opinion. For example, if a subject responded that it was too hot at $78^{\circ} \mathrm{F}$, too cold at $75^{\circ} \mathrm{F}$, and then too hot again at $78^{\circ} \mathrm{F}$, the temperature at which that subject would be most comfortable was inferred to be between 75 and $78^{\circ}$ F. For each trial in Phase 2, the measures of net irradiance, skin temperature, and air temperature were averaged over the first two opinion reversals. These average measurements were used to estimate the conditions under which the subject found the vehicle cabin comfortable. In the above example, an air temperature of $76.5^{\circ} \mathrm{F}\left(24.7^{\circ} \mathrm{C}\right)$ would be the estimate of the subject's comfort point. For the two cases in which a reversal of opinion never occurred (i.e., comfort was never reached), the lowest air temperature that the subject experienced in that trial was used as the subject's comfort point. 
The analyses were intended to answer the following question: Were there significant differences in net irradiance, skin temperature, and air temperature among the three IRR treatment conditions when subjects found the vehicle cabin comfortable?

\section{Net irradiance}

The mixed-effects ANCOVA for net irradiance included the factors of age group, gender, and IRR treatment, while controlling for differences in ambient irradiance. As expected, there was a significant effect of IRR treatment, $F(2,25)=245.1, p<.001$. Table 10 shows the estimated marginal means (equated on the covariate) of net irradiance for each level of IRR treatment. Notice that the relative values are very similar to those recorded in Phase 1 (see Table 3). There was a $35.9 \%$ decrease in net irradiance between no treatment and one layer of treatment and there was a $31.4 \%$ decrease between one and two layers of treatment.

Table 10

Phase 2 net irradiance for each level of IRR treatment.

\begin{tabular}{|c|c|}
\hline Condition & $\mathrm{W} / \mathrm{m}^{2}$ \\
\hline \hline No treatment & 404.68 \\
\hline One layer & 259.52 \\
\hline Two layers & 177.97 \\
\hline
\end{tabular}

\section{Skin temperature}

The mixed-effects ANCOVA for skin temperature included the factors of age group, gender, and IRR treatment, while controlling for differences in ambient irradiance. The analysis showed no significant differences in skin temperature among levels of age group, gender, or IRR treatment.

\section{Air temperature}

The mixed-effects ANCOVA for air temperature included the factors of age group, gender, and IRR treatment, while controlling for differences in ambient irradiance. The effect of IRR treatment was significant, $F(2,17.1)=10.9, p<.01$. Table 11 shows the estimated marginal means (equated on the covariate) of air temperature for each level of IRR treatment. Notice that, as expected, the mean air temperature when subjects were comfortable was lower in the control 
(no treatment) condition versus the one- and two-layer conditions. Although the air temperature is the highest in the one-layer condition-not the two-layer condition as might have been expected-Bonferroni tests of pairwise comparisons showed that there was no significant difference between the one- and two-layer conditions. Both the one- and two-layer conditions were significantly different from the control condition.

Table 11

Phase 2 mean air temperature for each level of IRR treatment.

\begin{tabular}{|c|c|c|}
\hline Condition & ${ }^{\circ} \mathrm{F}$ & ${ }^{\circ} \mathrm{C}$ \\
\hline \hline No treatment & 78.25 & 25.69 \\
\hline One layer & 81.01 & 27.23 \\
\hline Two layers & 80.60 & 27.00 \\
\hline
\end{tabular}

Because there was no significant difference between the one- and two-layer conditions, these two conditions were collapsed in order to compare the mean air temperatures between two groups: IRR treatment versus no IRR treatment.

A second mixed-effects ANCOVA was performed that included the factors of IRR treatment (treated vs. nontreated), age group, and gender while controlling for differences in ambient irradiance. The effect of IRR treatment was significant, $F(1,8.0)=26.3, p<.01$. Subjects found the IRR-treated conditions comfortable at an average of $78.3^{\circ} \mathrm{F}\left(25.7^{\circ} \mathrm{C}\right)$ and found the untreated condition comfortable at an average of $80.8^{\circ} \mathrm{F}\left(27.1^{\circ} \mathrm{C}\right)$, a difference of $2.5^{\circ} \mathrm{F}\left(1.4^{\circ} \mathrm{C}\right)$. 


\section{DISCUSSION}

\section{Phase 1}

Hypothesis: When air temperature is held constant, subjects will find an IRR-treated condition more comfortable than an untreated condition.

The IRR treatment showed a greater localized effect (on the left forearm) than it did on whole body thermal comfort. This was true after controlling for any differences in ambient irradiance and air temperature among IRR treatment conditions. The ratings of whole body comfort followed the same trend as the left forearm rating, but the magnitudes of the differences were not large enough to reach statistical significance. This is not entirely surprising, given the radiant asymmetry inside the vehicle cabin; one would not expect to see an effect of IRR treatment on areas of the body not exposed to direct radiation. (This is reflected, for example, when comfort ratings are collapsed across independent variables. Specifically, subjects gave the highest/hottest ratings to their left forearm, lower ratings for their whole body, and the lowest ratings for their left leg, regardless of IRR treatment.) However, because whole body comfort is the primary measure of interest, it is worth exploring why a main effect of IRR treatment was not found on this variable.

There are several possible reasons why the main effect of IRR treatment on whole body thermal comfort was nonsignificant. First, recall that one layer of the IRR film rejected $77 \%$ of infrared radiation. A film that rejected a higher percentage of IR may have yielded larger effects. Second, the subjects experienced direct solar irradiance from only one location: the driver-side window. This is a small surface area relative to the total amount of glazing in a typical car. If the subjects had been exposed to irradiance from multiple angles (especially through the windshield), the magnitude of the observed effect of IRR treatment may have been larger. Third, the two nominal air temperature levels may not have been specifically ideal for finding an effect of IRR treatment. If the higher air temperature was held at $100^{\circ} \mathrm{F}\left(37.78^{\circ} \mathrm{C}\right)$ instead of $90^{\circ} \mathrm{F}$, for example, subjects may have reported larger differences in comfort in response to the IRR treatment.

The interaction between IRR treatment and trial repetition also points to an interesting possibility - that length of exposure may be an important factor in determining whole body 
comfort. Table 12, for example, shows a typical block of trials for one nominal temperature condition in Phase 1. Within each repetition, the presentation order of IRR treatment conditions was randomized. Although the IRR treatments were randomized, repetition \#1 was always followed by repetition \#2. In other words, by the time repetition \#2 began, the subjects had already been in the car for approximately six minutes.

Table 12

Example of trial repetitions during Phase 1.

\begin{tabular}{|c|c|}
\hline Repetition & Treatment \\
\hline \multirow{3}{*}{1} & One layer \\
\cline { 2 - 2 } & No treatment \\
\cline { 2 - 2 } & Two layers \\
\hline \multirow{3}{*}{2} & No treatment \\
\cline { 2 - 2 } & Two layers \\
\cline { 2 - 2 } & One layer \\
\hline
\end{tabular}

Recall that the interaction between trial repetition and IRR treatment showed that subjective ratings of whole body thermal comfort moved away from "comfortable" (in the "hot" direction) as a function of repetition for the control (no treatment) condition, but that the reverse was true for the one- and two-layer conditions. This may suggest that the effect of the IRR treatment was more salient as a function of time (or length of exposure).

\section{Phase 2:}

Hypothesis: Subjects will require a lower air temperature in the untreated condition vs. the treated condition to maintain the same level of comfort.

In Phase 2, it was found that IRR treatment was associated with earlier reversals of opinion (from "too hot" to "too cold). For example, no subjects found the two-layer condition too hot beyond 14 minutes into the trial, whereas two subjects still found the untreated condition too hot (i.e., never made a reversal of opinion) at the end of the 20-minute trial. While this is consistent with findings from Phase 1, it also lends support to the conclusion that whole body thermal comfort is associated with the reduced net irradiance caused by the IRR treatment. 
When the air temperature in the vehicle cabin was examined as a dependent measure, significant differences were found between the control (no treatment) condition and the both the one- and two-layer conditions. The difference, however, between the one- and two-layer conditions was nonsignificant. Given the diminishing returns of reductions in net irradiance observed with the second layer of IRR treatment, it is plausible that subjects did not differentiate as much between the one- and two-layer conditions as they did the untreated versus treated conditions.

When comparing the untreated and treated conditions, it was found that subjects required a significantly lower air temperature in the untreated condition. Stated another way, in the IRRtreated conditions, subjects remained comfortable at an average of $2.5^{\circ} \mathrm{F}\left(1.4^{\circ} \mathrm{C}\right)$ higher than in the control condition. This figure can be directly compared with the results from studies that have examined IRR treatment's effect on fuel economy. For example, one method of predicting fuel economy savings is known as coheating (Farrington, Rugh, \& Barber, 2000). In a coheat test, the heater power required to maintain a given cabin air temperature (with constant A/C output) is measured. The difference in heater power between an IRR-treated glazing and a nontreated glazing represents the amount by which the A/C compressor size could be reduced, thereby reducing engine strain. One such study found that using an IRR windshield permitted a compressor reduction of about $400 \mathrm{~W}$, or a savings of about $0.7 \mathrm{mpg}(0.3 \mathrm{~km} / \mathrm{L})$ in fuel economy when the cabin was held at $140^{\circ} \mathrm{F}\left(60^{\circ} \mathrm{C}\right)$ (Farrington et. al, 2000). Another study predicted a $0.2 \mathrm{mpg}(0.09 \mathrm{~km} / \mathrm{L})$ increase in fuel economy based on a similar coheat test (Rugh, Farrington, \& Boettcher, 2001).

These estimates of fuel economy rest on the assumption that an IRR-treated vehicle's $\mathrm{A} / \mathrm{C}$ system would require less work to maintain a given air temperature. The results from Phase 2 of the present experiment, however, suggest that it is not necessary to maintain the same air temperature in an IRR-treated vehicle because occupants will find a higher air temperature just as comfortable. Another way of stating this is that IRR treatment's reduction of radiant heat "buys" $2.5^{\circ} \mathrm{F}\left(1.4^{\circ} \mathrm{C}\right)$ of air temperature. If this figure was taken into account, predicted savings in fuel economy would probably be larger.

The results from Phase 2 of the present experiment can also be compared with studies that have measured peak air temperatures of IRR-treated vehicles during soak-tests. For example, some studies have reported reductions in peak air temperature ranging from $3.2^{\circ} \mathrm{F}$ 
$\left(1.8^{\circ} \mathrm{C}\right)$ to $29^{\circ} \mathrm{F}\left(16.1^{\circ} \mathrm{C}\right)$ when IRR treatment is used on all glazing surfaces of the vehicle (Rugh et. al, 2001; Young \& van Esso, 1989). The results from the present experiment suggest that IRR treatment offers advantages that extend beyond air temperature reduction. It may not be necessary to achieve such high levels of air temperature reduction if a reduction in radiant heat is already mitigating some occupant discomfort.

\section{Future research}

The present study was performed within a limited range of ambient weather conditions. The location, season, time of day, and total length of each session were all factors that helped determine the range of ambient air temperatures and solar irradiance during the study. Future studies should explore a wider range of these variables to determine whether IRR treatment may have different effects in other environments.

Future studies should also examine how the amount and duration of radiant exposure affects whole body thermal comfort. In the present study, only one side of the subject was exposed to direct radiant heat, and was only exposed to that heat for a maximum of 20 minutes. It is still unclear how IRR treatment may affect thermal comfort in long-term (several hour) driving scenarios in which the subject is exposed to multiple angles of solar irradiance. 


\section{SUMMARY}

An experiment was performed to establish and quantify a relationship between radiant heat and subjective assessments of thermal comfort in a stationary vehicle. Specifically, the reduction of radiant heat associated with the application of an IRR treatment was examined. It was hypothesized that subjects would find the IRR-treated condition more comfortable than the untreated condition when air temperature was controlled, and that subjects would require a lower air temperature in the untreated condition in order to maintain the same level of comfort.

The IRR treatment significantly improved ratings of localized thermal comfort (on the left forearm, which was exposed to direct solar irradiance) when air temperature was held constant. Although the ratings for whole body thermal comfort followed the same trend, the difference was not statistically significant. Subjective ratings also roughly corresponded to the amount of direct radiant exposure at a particular body location-direct radiation resulted in higher (hotter) ratings.

When air temperature was adjusted, the IRR treatment was associated with earlier reversals of opinion (from "too hot" to "too cold"). In addition, subjects' reported comfort level was an average of $2.5^{\circ} \mathrm{F}\left(1.4^{\circ} \mathrm{C}\right)$ cooler in the untreated condition than in the treated conditions, a difference that was statistically significant.

The results support the conclusion that reducing radiant heat by the application of an IRR treatment affects subjective assessments of thermal comfort. This implies higher savings in fuel economy than has been shown in previous studies because the $\mathrm{A} / \mathrm{C}$ system can allow a higher air temperature in an IRR-treated car while still maintaining passenger comfort.

The range of conditions investigated in this study was limited, and the results should therefore be considered preliminary. Future research should examine how the following factors influence the relationships observed in this study: the percentage of IR rejection provided by the treatment, the total surface area of the treatment, the duration and amount of the subjects' irradiant exposure, and a wider range of ambient weather conditions. 


\section{APPENDIX}

\section{Subject Instructions}

Thank you again for your participation in this study. Today's procedure will consist of two separate phases, which are outlined below.

$\underline{\text { Phase I }}$

Phase I will take approximately 40 minutes and will consist of two 15-minute sets of trials with a ten-minute break in between. At the beginning of each set of trials, the experimenter will lead you outside to the car in the parking lot. Only when the experimenter prompts you to enter the car (not before), please open the driver-side door, and enter the car as quickly as possible. You do not need to worry about putting on your seatbelt or making any adjustments to the seat or other controls. Just open the door, get into the driver-seat, and close the door as soon as you can. Again, you should not make any adjustments to the car's interior.

After you enter the car, the experimenter will attach the four skin temperature sensors on your clothes to the appropriate connectors in the car. This will take a few moments. At this time, the experimenter will ask you to put on the blindfold, and will then ask you to place your hands on the steering wheel as if you were driving. The experimenter will indicate exactly where on the steering wheel your hands should be placed.

You will then be asked by the experimenter to give several ratings of your thermal comfort every two minutes until a period of about 12 minutes has elapsed. Do not worry about keeping track of time - the experimenter will prompt you for ratings every two minutes and will let you know when the 12 minutes are over.

Once the 12 minutes have elapsed, you may remove the blindfold, and the experimenter will disconnect the sensor attachments on your clothes. You will then be led back into the cafeteria area for 10 minutes before the next set of trials begins.

\section{$\underline{\text { Phase II }}$}

Phase II will take approximately one hour and 20 minutes, and will consist of three 20minute trials, with 10-minute breaks in between each trial. This phase of the experiment will work in very much the same way as Phase I, but with a few minor differences. At the beginning of each trial, the experimenter will lead you outside to the car. Again, wait until the experimenter tells you to enter, and then enter the car as quickly as possible and close the door. After putting on the blindfold and connecting the skin temperature sensors, the trial will begin.

In this phase of the experiment, you will not be giving ratings of your thermal comfort. Instead, you will simply tell the experimenter whether you are too hot or too cold. In other words, there is no "comfortable" in this part of the study; every time the experimenter asks, you must either say that you are too hot or too cold, even if you are only slightly so. If you do feel perfectly comfortable, try your best to determine whether you would ideally like it a bit warmer or cooler, and indicate either "too cold" or "too hot" to the experimenter when you are prompted.

You will be asked to indicate whether you are too hot or too cold every two minutes until a period of 20 minutes has elapsed. Again, do not worry about keeping track of time; the 
experimenter will let you know when it is time to take off the blindfold and go back into the UMTRI building.

Please take a moment now to look at the scale we will ask you to use for the first part of today's study. This scale relates to how comfortable you feel. The scale has nine points, from -4 (very cold), 0 (comfortable), to +4 (very hot). Please note that we are not asking how you would rate the environment, but rather how you feel. For example, if you were jogging outside in the wintertime, you may rate the environment as cold while you may actually feel hot. We will ask you to use this scale to give three ratings of your thermal comfort: an overall rating (how hot, cold, or comfortable your entire body feels), a left forearm rating (how hot or cold your left forearm feels), and a left leg rating (how hot or cold your left leg feels). To give a rating, simply call out the number that corresponds to how you feel at that moment. The experimenter will record your responses.

Please take a moment to familiarize yourself with this scale, as you will not be able to refer to it throughout today's session.

We urge you again to notify the experimenter immediately if at any time you feel dizzy, light-headed, or otherwise too uncomfortable to continue. Remember that water will be available to you whenever you are not in the car.

Before we get started, do you have any questions? 


\section{REFERENCES}

ASTM E891-87 (1992). Tables for Terrestrial Direct Normal Solar Irradiance Tables for Air Mass 1.5. West Conshohocken, PA: American Society of Testing and Materials.

ASTM E892-87 (1992). Tables for Terrestrial Solar Spectral Irradiance at Air Mass 1.5 for a 37-Deg Tilted Surface. West Conshohocken, PA: American Society of Testing and Materials.

Devonshire, J. \& Sayer, J. (2002). The effects of infrared-reflective and antireflective glazing on thermal comfort and visual performance: a literature review (Technical Report UMTRI2002-4). Ann Arbor: The University of Michigan Transportation Research Institute.

Devonshire, J. \& Sayer, J. (2003). The effects of infrared-reflective treatment on thermal comfort during transient conditions (Technical Report UMTRI-2003-3). Ann Arbor: The University of Michigan Transportation Research Institute.

Fanger, P.O. (1970). Thermal Comfort: Analysis and Applications in Environmental Engineering. USA: McGraw-Hill Book Company.

Farrington, R.B., Rugh, J.P., \& Barber, G.D. (2000). Effect of solar-reflective glazing on fuel economy, tailpipe emissions, and thermal comfort. SAE paper no. 2000-01-2694. Presented at the 2000 International Body Engineering Conference and Exposition (IBEC). pp. 1-8.

Hymore, R.R., Tweadey, R.F., and Wozniak, D.F. (1991). Development of a test procedure for quantifying performance benefits of solar control glazings on occupant comfort. SAE Technical Paper Series, no. 910536. 8 pp. Society of Automotive Engineers: Warrendale, PA.

ISO 9886. (1992). Evaluation of thermal strain by physiological measurements. Geneva: International Standards Organization.

ISO 10551. (1993). Assessing the influence of the thermal environment using subjective judgment scales. Geneva: International Standards Organization. 
"Measured radiation quantities." (2003). National Oceanic and Atmospheric Administration's Climate Monitoring \& Diagnostics Laboratory. Available: http://www.cmdl.noaa.gov/ star/starmeas.html.

Moyer, K.L. (1995). Analytical and empirical evaluation of the impact of solar control glazing on the thermal environment in vans. SAE Technical Paper Series, no. 950052. 13 pp. Society of Automotive Engineers: Warrendale, PA.

Roessler, D.M. \& Heckmann, T. (1992). Which automotive glazing makes me feel more comfortable. SAE Technical Paper Series, no. 920263. 8 pp. Society of Automotive Engineers: Warrendale, PA.

Rugh, J.P., Farrington, R.B., \& Boettcher, J.A. (2001). The impact of metal-free solar reflecting film on vehicle climate control. SAE Technical Paper Series, no. 2001-01-1721. 7 pp. Society of Automotive Engineers: Warrendale, PA.

"Solar radiation basics." (2002). University of Oregon Solar Radiation Monitoring Laboratory. Available: http://solardat.uoregon.edu/SolarRadiationBasics.html.

SPSS technical report. (2002). Linear mixed-effects modeling in SPSS: An introduction to the MIXED procedure. SPSS Inc.: Chicago, IL

Young, P. \& Van Esso, R.A. (1989). A solar control glass for automobiles. SAE Technical Paper Series, no. 890311. 16 pp. Society of Automotive Engineers: Warrendale, PA. 